\title{
Interventional Pain Management in the New Millennium
}

\section{Laxmaiah Manchikanti, MD}

“....There is no limit to what a man can do or where he can go if he doesn't mind who gets the credit."

-- Ronald Reagan

The statement of former President Ronald Reagan, described as one of the greatest communicators of our times, reflects the current state of affairs of interventional pain medicine in the United States. The converse of this statement describes the philosophy of many other organizations representing pain physicians, surgery centers and others. It seems that the new philosophy is "there is no limit to what a man can do or take credit for or where he can go if he doesn't mind taking credit for the things he has never done or in which he had minimum involvement.”

I was recently enjoying the successes for interventional pain medicine, such as the restoration of lysis of adhesions in Florida; lobbying for increased levels of reimbursement for lumbar neurolytic blocks, discography, and other radiological procedure; and finally, the major achievement: the addition of nine long awaited codes to the Ambulatory Surgery Center (ASC) approved procedure listing. I believe that I was justified in enjoying the successful resolution of the above problems, not only as a personal achievement but also as a triumph for our organization. With great assistance from some of our members and additional support from the entire membership, we alone fought for the specific issues. Then I started receiving notices from various organizations, including the North American Spine Society, the Federated Ambulatory Surgery Center Association, and the Society for Pain Practice Management, regarding the successful restoration of ambulatory surgery codes. However, none of these organizations bothered to give any credit to the American Society of Interventional

From the American Society of Interventional Pain Physicians, Paducah, Kentucky. Dr. Manchikanti is the President and Executive Director of the American Society of Interventional Pain Physicians. Address correspondence: Laxmaiah Manchikanti, MD, 2831 Lone Oak Road, Paducah, KY 42003. Email: drm@asipp.org
Pain Physicians. As you all know, we have tirelessly worked on restoring the codes with lobbying from patients and physicians (letters, phone calls, personal meetings), which resulted in 18 letters of support from Congress and finally a meeting with several key officials at HCFA attended by myself, David Kloth, M.D.; Peter Wright, M.D.; Joseph Waling, M.D.; and William Sarraille, J.D.

You can understand my frustration.

I wrote to the North American Spine Society and the Federated Ambulatory Surgery Center Association. While I never heard from the North American Spine Society, the Federated Ambulatory Surgery Center Association replied that it actually thought that their letter, on which they spent several hours, made the difference. Dr. Kloth corresponded with Dr. Waldman, President of the Society for Pain Practice Management for sending such a flash bulletin. Fortunately, Dr. Waldman did agree that he was not taking credit for this in any form, even though the letter did not reflect that. In addition, Dr. Waldman also felt that the Society for Pain Practice Management was the only organization fighting for these issues and he was happy to know that there were other organizations that were involved.

The bottom line is that every organization wants to take credit for these accomplishments. I am not denying an opportunity for any of these organizations to lobby or take credit; however, they have not lobbied for these specific issues, even though they generally lobbied for certain issues by writing one or a few letters. Our organization is the only one that took multiple steps to achieve the present status. I hope interventional pain physicians will appreciate what Winston Churchill once said: "True genius resides in the capacity for evaluation of uncertain and conflicting information.” News flash!! It is no surprise that we, as physicians in general and interventional pain medicine physicians in particular, are bombarded with not only uncertain but quite conflicting information on a daily if not an hourly basis.

As if this was not enough, I received a letter from one of the non-anesthesiology interventional pain specialists that 
stated, "I applaud your change in name as it will make it far more likely to draw non-anesthesiologists such as myself to your membership. I have been receiving excellent information in the form of journals and newsletters from your organization, which have been extremely useful in my practice. However, I am not a member and am not yet convinced of the need to join your organization, but as always I support all your efforts.” I am sure this interventional pain physician is a member of the greatest organizations representing interventional pain medicine and paying dues of two to three times more than our organizations to each organizations. Then I was reminded of our mission statement, which states: "To promote the development and practice of safe, high quality, cost effective interventional pain medicine techniques for the diagnosis and minimally invasive treatment of pain and related disorders, and to ensure patient access to these interventions." At this time, I am not quite sure how to respond to physicians, as above, who take advantage of the benefits and do not offer support in a meaningful way. Of course, this may be better than the ones who not only take the credit but also criticize the achievements.

On the other hand, there are also many who express appreciation, admiration, and gratefulness to the organization for its efforts. In the business world, whether it is fair or not, one negative comment will spread to 16 people, thus six negative comments will spread to 96 people, but four positive comments will go only to a total of 16 instead of 96. Some of the uplifting comments include:

- $\quad$ "ASIPP is the most exciting organization - significant things get accomplished!”

— Mary Jo Curran, M.D.

- "I want to thank you personally for the Herculean effort that you have accomplished in the name of patient care and for our specialty.”

\section{- Steve Minore, M.D.}

- $\quad$ "I am quite impressed by your tenacity and involvement with the society and would like to help."

— Tony Sabatino, M.D.

- “Thanks again for all your hard work."

- Kenneth Varley, M.D.

- "Great news is right!"

_ Gabor B. Racz, M.D.

- "I am very impressed with your efforts in D.C., with Congress and HCFA. The ASA and the AMA have never championed our specialty.”

— Michael McKenna, M.D.

- $\quad$ "I would like to commend you on your impres- sive accomplishments with the development of this society. The society has given a small specialty in medicine (pain management) a much needed forum and voice. The journal is absolutely top rate. Thank you for all of your hard work in bringing together such an organization.” Johnathan Kost, M.D.

"I applaud you for your great work and commitment to pain medicine.”

- Reuben Hoch, M.D.

- “Thank you for your leadership. Please don't give up.”

— Robert A. Hamilton, M.D.

"Thank you for making such a dramatic difference in our new speciality.”

— John Swicegood, M.D.

"Strong work!! Thanks for your efforts."

— David Gale, M.D.

"Congratulations on the outstanding success you and our organization achieved.”

_ Sairam Atluri, M.D.

"Congratulations and of course our thanks for your continued intensity of working with and when need be against HCFA.”

Craig DuBois, M.D.

"I just wanted to thank you for your very informative e-mails. Please keep up the excellent work."

— James Rho, M.D.

Of course, I have received many more of these.

I am proud to state that ASIPP is an active, vibrant organization, slowly gaining the recognition it deserves not only among interventional pain specialists but also with legislative and executive branches. Thus, the Board of Directors, the Executive Committee, and other members of the organization are working closely to achieve our goals. ASIPP leadership is working hard on your behalf to ensure that the organization is doing its utmost for you and your practice of interventional pain medicine, whether it is in a setting of a surgery center, office, or hospital. While our goals are broad and inclusive, as described in Table 1, we continue to chart a future direction for ASIPP. One of the major goals is to create a unity of purpose for ASIPP and its members and to ensure that ASIPP is operating in an effective and efficient manner on behalf of its members. By the end of 2001, I would like to see ASIPP dues paying membership to increase from nearly 700 now to 1200.

In its short history, it has achieved much and made its presence known by various activities (Table 2). Seven of these 


Table 1. Goals of the American Society of
Interventional Pain Physicians
To preserve coverage for interventional
pain medicine
To advance patient safety, cost effectiveness,
and accountability
To provide state of the art and interventional
pain medicine services
To communicate with legislators, patients,
public, HCFA, and third party payors
To uphold high principles, policies, and prac-
tices
To pursue excellence in education in inter-
ventional pain medicine
To improve practice management
To improve compliance
To eliminate fraud and abuse
To provide total pain care

ten achievements are entirely the result of the hard work of ASIPP, while we worked with other organizations on the remaining issues.

Thus, we are finally in a position of obtaining specialty designation for interventional pain medicine. The language of the bill is as follows:

SEC. 438. MEDPAC STUDY ON ACCESS TO

\section{OUTPATIENT PAIN MANAGEMENT SERVICES}

(a) STUDY - The Medicare Payment Advisory Commission shall conduct a study on the barriers to coverage and payment for outpatient interventional pain medicine procedures under the medicare program under title XVIII of the Social Security Act. Such study shall examine--

(1) the specific barriers imposed under the medicare program on the provision of pain management procedures in hospital outpatient departments, ambulatory surgery centers, and physicians' offices; and

(2) the consistency of medicare payment policies for pain management procedures in those difference settings.

(b) REPORT - Not later than 1 year after the date of the enactment of this Act, the Commission shall submit to Congress a report on the study.

As you read the language, it also opens up other possibilities to demonstrate our case, not only with specialty recognition regarding the practice expense issue but also with various other issues including access to interventional pain medicine services in the physician office, hospital and ambulatory surgical settings.

This only happened with aggressive grassroots campaign-

Table 2. Major (top ten) achievements of the American Society of Interventional Pain Physicians

- Inclusion of nine new or replacement codes in ASC approved list

- Restoration of reimbursement at a higher level for lumbar facet joint neurolytic procedures, discography, and multiple radiology procedures

- Approval of lysis of adhesions by Florida Medicare, which was previously classified as experimental

- Specialty designation - a legislative enactment leading to favorable opinion on consideration of specialty designation by HCFA

- H.R. 3146: Phase-In of PPS for Ambulatory Surgery Centers

- Legislative achievement delaying the implementation of ASC prospective payment system until 2002 and an extension of phase-in of the system over a period of 4 years

- Reversal of decision to delete multiple pain management codes from ASC approved list

- Consideration of ASIPP members to serve on Carrier Advisory Committees at state level

- Redesigning of rules for facet joint injections and neurolytic blocks in Kentucky and Indiana

- Eighteen letters of support on various issues of interventional pain medicine from congressional membership 
ing and bipartisan Congressional support. Because of this, HCFA is considering these issues in a positive light and also because of the Medicare Refinement Act of 2000, sponsored by Congressman Ed Whitfield (R-KY), and Frank Pallone (D-NJ). It unanimously passed through the Commerce Committee with bipartisan support. The final version was modified by representative Bill Thomas (RCA) to conduct an initial study by MedPAC to demonstrate higher practice expenses for interventional pain physicians. The study results will be reported in 12 months to Congress, which will act after that. Subsequently, the bill went through the Senate Conference Committee and finally was signed by President Clinton.

However, strangely — but not surprisingly — I have heard criticism of this bill from our friendly pain medicine organizations. In an interview focused on what is working in "Pain Practice Management: Success strategies to build your pain practice," a reporter stated, "ASIPP's efforts have some in the anesthesia community scratching their heads," adding that, "Pain physicians have already benefited handsomely from Medicare's decision not to pay anesthesiologists for clinical staff in the hospital. ...” Her argument, and that of some uninformed billing experts, is that because Medicare views pain management physicians as anesthesiologists, pain physicians have seen fees for procedures performed in an office or clinic soar in the last two years. Anesthesia reimbursement meanwhile has dropped slightly, while Medicare made substantial cuts in fees for pain procedures performed in a hospital. According to this reporter, ASIPP's lobbying effort has sparked a turf war between it and other pain groups, which would prefer HCFA to recognize a "broader pain medicine" subspecialty, not the narrower "interventional pain management." Bob Saner, an attorney representing the Pain Care Coalition (PCC), a lobbying group made up of pain associations, including the American Pain Society and the American Academy of Pain Medicine, stated, "The organization I represent doesn't think it is the appropriate fix. Instead, the PCC is lobbying for a Medicare pain medicine category that would include physiatrists, chiropractors, and other non-anesthesiology practitioners.” He continued to state, "Our groups belief is pain is a very large public health problem and is understudied and underrepresented in the national health care debate, because Medicare doesn't expressly recognize pain medicine, even though it recognizes some subspecialties." Saner believes that if interventional pain medicine physicians receive a special recognition from HCFA, it would only help anesthesiologists. He says payors would pay for procedures done by an anesthesiologist but not by a neurologist, even though that doctor would be as specialized. Saner also stated that most of the procedures done under interventional pain management are performed by anesthesiologists, which might trigger payors to decide to recognize only anesthesiologists for reimbursement purposes. It appears that at the moment, "The PCC is not aggressively lobbying for Medicare's recognition of pain medicine as opposed to interventional pain management," the reporter stated. In addition, Saner also graciously stated that his group is not trying to affect the pending Medicare bill but will renew its lobbying efforts next year through members of Congress and HCFA. It was also reported that Mr. Saner stated, "This bill will not have any influence on physician reimbursement because pain specialists do not bill based on the time and units as anesthesiologists do."

I am not quite sure where to start and how to proceed with these comments. Is this the ignorance of the lobbying group or is it the ignorance of our pain medicine organizations, including the premier organization, the American Academy of Pain Medicine, and the largest organization, the American Pain Society? This is not only a pathetic attempt to justify their ambivalence and inaction but also reflects galactic ignorance. Once again, Mr. Saner reinforces the fact that these organizations consider anesthesiologists as outsiders and probably enemies. (Unfortunately, I am a member of both these organizations.) This type of response is extremely detrimental to the specialty of interventional pain medicine. The ignorance of not only Mr. Saner, but also so-called anesthesiology billing experts is incomprehensible. In fact, specialty recognition for interventional pain management will affect about 30\% to $35 \%$ of the practice expense in a physician fee; however, this will not have any effect on the practice management expenses of anesthesiology, as they are so low. In addition, the American Society of Interventional Pain Physicians represents all types of physicians, not just anesthesiologists. The membership composition of the American Society of Interventional Pain Physicians is not any different than other organizations, which are of course dominated by anesthesiologists in spirit (but not by rule). The difference is that we recognize the importance of all specialists, including anesthesiologists, rather than collect the funds derived from anesthesiologists but work against the anesthesiologists ignoring the old saying; “don’t bite the hand that feeds you." As you know, the practice expenses are developed separately for each recognized specialty. Thus, practice expense values for most interventional procedures are derived from anesthesiology, even though a proportion of the procedures are performed by other specialists. For example, if a procedure is performed $80 \%$ of 
the time by anesthesiologists, $5 \%$ by neurologists, $5 \%$ by physiatrists, $5 \%$ by orthopedic surgeons, and $5 \%$ from various other specialties, the practice expense component is also derived accordingly, based on the proportionate percentages. Thus, practice expense calculation does make a difference. In fact, hourly practice expense data for all physicians per the 2000 physicial fee schedule is $\$ 68.00$, dermatology is $\$ 115.00$, pathology is $\$ 47.00$, neurology is $\$ 59.00$, physical medicine rehabilitation is $\$ 88.00$, in contrast to the anesthesiology practice expense of a meager $\$ 27.00$ per hour, less than pathology. Of course, lack of subspecialty recognition also results in lack of representation on Medicare Carrier Advisory Committees (CACs), which is not only an extremely important component of the local Medicare Review Policy making, but also ensures representation of interventional pain medicine. However, it appears that criticism does not stop right there. The well-meaning lobby of American Society of Anesthesiologists (ASA), confounded by pressures of hospital based anesthesia coupled with a lack of appropriate knowledge, and with overenthusiastic attitudes is providing advice to naive pain specialists and anesthesiologists continues to destabilize and damage the specialty. One of the billing experts said, "It is a psychological boost - Manchikanti is shaking every bush to get more members.” Misinformed so called "soaring physician reimbursement" was not caused by increased physicians fees but because procedures can be performed in the office settings in addition to ambulatory surgery and the hospitals. The increase in reimbursements has been secondary to a defacto facility expense portion for the office. In fact, the physician fee for pain procedures has been reduced substantially over the years. Considering inflation, reimbursement for lumbar epidural steroid injection has been reduced 69\% in 2001, compared to the reimbursement in 1988. The specialty recognition will increase the practice expense portion of the physician fee and has nothing to do with facility fee for the office, surgery center, or the hospital. Some anesthesiologists are also confused by this phenomenon and have certain misgivings, resulting in opposition to office based interventional pain management. ASIPP is opposed to any type of interventional pain management in an unsafe environment or unscientific manner. On the other hand, appropriately conducted office practice should be encouraged. Unfortunately, Medicare reimbursement at this stage does not sufficiently cover the expenses of a physician to embark on this endeavor, and many physicians do not make a profit by providing this service in the office instead of surgery center or hospital. All concerned should realize that the fees paid for the non-facility portion in the physician fee schedule cover drugs, supplies, facility, c-arm, nurses, technicians, and other personnel.

In addition to the above, we also have achieved significant progress with the introduction of another bill allowing for the phase-in of prospective payment system for Ambulatory Surgery Centers over a period of four years and implementation of the final rule of ASCs to be delayed until January 2002. Even though ASIPP was only a signatory and nothing specifically was said about interventional pain medicine, pain medicine will benefit because of the improved access to patient care. However, this bill was also passed through the Congress on behalf of ASIPP, and was again sponsored by Congressman Ed Whitfield, (R-KY), and co-sponsored by Congressman Frank Pallone, (D-NJ). This bill also passed both houses and was signed by President Clinton to become law. The language is as follows:

\section{SEC. 424. AMBULATORY SURGICAL CENTERS}

(a) DELAY IN IMPLEMENTATION OF PROSPECTIVE PAYMENT SYSTEM.- - The Secretary of Health and Human Services may not implement a revised prospective payment system for services of ambulatory surgical facilities under section 1833 (i) of the Social Security Act (42 U.S.C. 13951(i)) before January 1, 2002.

(b) EXTENDING PHASE-IN TO 4 YEARS.-Section 226 of the BBRA (113 Stat. 1501A-354) is amended by striking paragraphs (1) and (2) and inserting the following:

"(1) in the first year of its implementation, only a proportion (specified by the Secretary and not to exceed $1 / 4$ ) of the payment for such services shall be made in accordance with such system and the remainder shall be made in accordance current regulations; and

"(2) in each of the following 2 years a proportion (specified by the Secretary and not to exceed $1 / 2$, and $3 / 4$, respectively) of the payment for such services shall be made under such system and the remainder shall be made in accordance with current regulations."

(c) DEADLINE FOR USE OF 1999 OR LATER COST SURVEYS.-Section 226 of BBRA (113 Stat. 1501A-354) is amended by adding at the end the following:

"By not later than January 1, 2003, the Secretary shall incorporate data from a 1999 medicare cost survey or a subsequent cost survey for purposes of implementing or revising such system.” 
Once again, I may be criticized for working towards improvement for ASC reimbursements. But remember, this is not only an issue about ASCs but also for access to interventional pain procedures. If ASCs refuse to do interventional pain procedures, you lose one site of service; if hospitals refuse to do these services, you lose the second site. Finally, you have to resort to office practices even if you are unwilling it is occasionally unfeasible. It will be extremely difficult to provide access to the patients to have the procedures done and access to the physicians to perform the procedures.

Thus, I have no regrets for these achievements. I also have no regrets for all the interventional pain specialists and other surgical specialists and surgery centers who benefit from this legislation. I hope they will recognize the effort of ASIPP and accordingly contribute their support.

Other activities include a successive and heavy letter campaign of ASIPP sending over 18,000 letters to HCFA, legislators, and the administration on various issues and making pain management a hot topic, not only with HCFA but in the halls of Congress and with the public. This resulted not only in 18 letters of congressional support on various issues, but also in several phone calls from legislators to HCFA, and HCFA's willingness to listen to us. Further, we held two very highly successful annual meetings in Washington, D.C. This does not mean that we haven't had any glitches, but for a budding organization with basically no resources, it is a significant achievement. One of the most important aspects of the annual meetings was the legislative initiative that we implemented following the second annual meeting, resulting in meetings of our members with over 70 congressional members.

Our publications and resources are also impressive. ASIPP is a resource center for letters to congressional members and HCFA. There are various newsletters published along with the Pain Physician journal and an active website. We also provide interventional pain specialists with a specialty specific compliance manual, policy and procedure manuals, practice guidelines, and a software package for evaluation and management services. Our Pain Physician journal is a peer-reviewed journal, awaiting recognition by Index Medicus. The objectives of Pain Physician journal are:

- To promote the science and art of interventional pain management and the betterment of the public health

- To publish original, important, peer-reviewed, clinical, laboratory, and review articles on a diverse range of topics in interventional pain management; invited review articles, and articles related to the practice of pain management To provide physicians and other providers with continuing education in political, business, and scientific aspects of interventional pain management to support informed clinical decisions

To foster responsible and balanced debates on controversial issues that affect interventional pain management and health care, and to forecast important issues and trends in pain management

- $\quad$ To achieve the highest level of ethical journalism and to produce a publication that is timely, practical, credible, easy-to-read and understand, and enjoyable

- To report policies of the American Society of Interventional Pain Physicians (ASIPP) as appropriate, while maintaining editorial independence, objectivity, and responsibility.

The Pain Physician is an academic journal that focuses not only on the study of pain medicine, but also the practice of pain medicine, which gives it a unique focus in today's pain medicine environment and goes beyond the practice of interventional pain medicine. It continues to be dedicated to publishing new but practical findings, while moving the field of interventional pain medicine forward, not only in terms of clinical involvement, but in promoting safe, efficacious practice. We continue to publish detailed review articles with long reference lists, along with original articles; not only prospective and randomized clinical trials but also good observational reports along with an equal focus on the practice of interventional pain medicine that may contribute to the very survival of the specialty itself. Thus, the mainstay of this journal is the publication of original articles in clinical practice settings, with major topical reviews, and about up-to-date legislative happenings and practice management. The journal is designed to keep interventional pain physicians abreast of the field, with steady improvement in the quality of the articles, as well as the publication itself. However, tough choices and responsibilities lie ahead of use; the survival of the journal -- as well as interventional pain medicine lies in the hands of the leadership and membership of ASIPP. The future is bright, not because we are at the threshold of exciting new discoveries of mechanisms of consistent and persistent pain and their management, but because we are on the verge of achieving an exciting relationship between interventional pain physicians and governmental providers, with the hope that this same relation- 
ship will extend to other providers, including HMOs, PPOs, Worker's Compensation organizations, and other payors. A daunting responsibility rests with us to communicate about the fast-moving advances in interventional pain medicine, the effectiveness of various modalities of interventional pain medicine, and the willingness of our membership to provide access and service to the patient population suffering with persistent pain while maintaining the most advanced ethical interventional pain medicine practices in a financially sound and clinically safe environment.

Our activity in political arena has been most rewarding. We not only have organized a successful PAC and supported several congressional candidates, but we have succeeded well with our lobbying efforts. Table 3 lists the contributions made to various candidates of the Senate and House from both parties.

We should recognize that organized medicine spends more than $\$ 85,000$ a day to speak on physicians behalf- to lobby congress, the White House, and sundry federal agencies. We can be assured that not even a fraction of this sum, mentioned in Medical Economics, goes towards the preservation of interventional pain medicine. If we believe that medicine is not an exact science but an art, lobbying is not even like medicine. Pundits say that lobbying does not have well-defined outcomes. It is believed that success is measured by an organization's capacity, either to get the bills passed or to block others' bills. Even then, the payoff is often not clear cut. As a result, most people think money buys votes in Washington. In addition, investigative journalists regularly report on the connection between money and power. One such example is that a strong body of evidence links pro-managed care industry campaign contributions and some of the senators strenuous efforts to defeat popular patient's rights legislation. However, this is not always true. PAC contributions to federal candidates for 1997 to 1998 election cycle (1999-2000 are not available yet) ranged from $\$ 43,075$ from the American Association of Health Plans to \$2,409,300 from the Association of Trial Lawyers of America, just ahead of the American Medical Association at \$2,323,781 (Table 4). However, the philosophy of ASIPP is to communicate directly to the legislators the issues of patient access and deleterious effects of certain laws rather than buy them with the money and express disrespect and arrogance. Political consultants feel that practicing physicians are much more effective at the influence game when they speak for themselves. My Congressman - Representative Ed Whitfield who has been extremely helpful — stated that communicating in a civilized manner to congressional staff personnel or to congressional committee staff always pays

Table 3. American Society of Interventional Pain Physicians-PAC contributions for 2000 election

\begin{tabular}{ll}
\hline Senator Durbin (D-IL) \$2000 & $\begin{array}{l}\text { Congressman Lewis (R-KY) \$5000 } \\
\text { Senator Lieberman (D-CT) \$2000 }\end{array}$ \\
Senator Lott (R-MS) \$3000 & Congressman Lucas (D-KY) \$6000 \\
Senator McConnell (R-KY) \$3000 & Congresswoman McCarthy (D-NY) \$3000 \\
Senator Nickles (R-OK) \$3000 & Congressman Phelps (D-IL) \$2000 $\$ 2000$ \\
Senator John Rockefeller (D-WV) \$3000 & Congressman Pickering (R-MS) \$5000 \\
Senator Ron Wyden, (D-OR) \$3000 & Congressman Rangel (D-NY) \$5000 \\
Congressman Brown (D-OH) \$5000 & Congressman Stark (D-CA) \$4000 \\
Congressman Crane (R-IL) \$3000 & Congressman Stupak (D-MI) \$5000 \\
Congressman Dingell (D-MI) \$5000 & Congressman Tanner (D-TN) \$2000 \\
Congresswoman Johnson (R-CT) \$4000 & Congressman Thomas (R-CA) \$5000 \\
Congressman Johnson (R-TX) \$3000 & Congressman Watts (R-OK) \$5000 \\
Congressman Kleczka (D-WI) \$3000 & Congressman Whitfield (R-KY) \$6000 \\
Congressman Lewis (D-GA) \$3000 & \\
\hline
\end{tabular}


off. Thus ASIPP tries to develop with staff members strong, trusting relationships, which will not only have a long lasting influence on a congressman's agenda or a committee's agenda also promotes subsequent communication from these members when they do make their decisions. However, ASIPP does not have the means of the American Medical Association or the American College of Physicians - the American Society of Internal Medicine, which assigns its lobbyists to committees rather than to issues. Nevertheless, thanks to the help of our membership, our contributions have been higher than the PAC of the North American Spine Society or the Kentucky Medical Association. But ASIPP'S PAC contributions, of course, pale in front of the American Society of Anesthesiologists PAC, which in 2000 contributed an unprecedented $\$ 1.6$ million. That puts ASIPP-PAC contributions at 7\% of ASA-PAC's contributions. Not surprisingly, ASA-PAC was able to raise $\$ 78,231$ in one year just in Texas.

ASIPP has also played a leading role in the development of proper guidelines for the practice of interventional pain medicine. These guidelines were published in the millennial issue (January 2000) of the Pain Physician. From its inception, the organization has been concerned not only about appropriate practice patterns of interventional pain medicine but utilization of the literature out of context, inapplicable literature, and inadequate representation of interventional pain medicine in the development of previous guidelines. Interventional Techniques in the Management of Chronic Pain: Part 1.0, Prac-

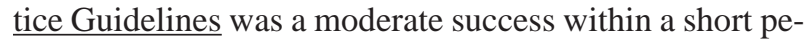
riod of time following publication. We continue to receive not only requests for reprints of these guidelines, and we are also excited by the offer by some providers to utilize these guidelines in developing their own guidelines. Since it has been approximately a year since the publication of Part 1.0, we have revised and published these guidelines in this issue with Interventional Techniques in the Management of Chronic Pain: Part 2.0, Practice Guidelines. As you will see, not only from the guidelines but the accompanying article on "The Role and Relevance of Guidelines in Interventional Pain Management: Separating Apples and Oranges", there have been many changes and additions. There is no shortage of clinical practice guidelines, but we continue to suffer from the lack of specific guidelines for interventional pain medicine. Thus, in staying with our goals to improve the quality of care and increase patient access and outcomes by providing appropriate care that is efficient and effective, the new guidelines take us a step closer to achieving our final goal of "total pain care."

Once again, I am sure we will face substantial criticism for developing the guidelines, especially from the many Dr. No's, who are constantly waiting to put down interventional pain medicine with their own anecdotal and self-propagating, inconsistent, pitiful opinions. When patient care is denied, one of two reasons is usually given for the denial. First, the service is not covered by the patient's insurance plan, which is secondary to the mostly ambiguous language and fine print of the policy. Second, the medical director or another reviewing physician does not consider the service appropriate for the patient's medical condition. These denials are supposed to prevent the provision of unnecessary and potentially harmful services to patients. In truth, the insurers and reviewers utilize this as a last measure to justify the denial of health care benefits when all else fails. As Linda Peno, M.D., a former medical director of a large HMO stated in her congressional testimony critical of HMOs, "When all else fails in trying to justify the denial

Table 4. PAC contributions from various organizations lobbying for health care issues to federal candidates for 1997-1998 election cycle

\begin{tabular}{lccc}
\hline Organization & Amount & \% to Democrats & \% to GOP \\
\hline Association of Trial Lawyers of America & $2,409,300$ & 87 & 13 \\
American Medical Association & $2,323,781$ & 28 & 72 \\
National Federation of Independent Business & $1,209,836$ & 7 & 93 \\
Blue Cross and Blue Shield Association & 347,114 & 32 & 68 \\
Health Insurance Association of America & 114,862 & 24 & 76 \\
American Association of Health Plans & 43,075 & 24 & 76 \\
\hline
\end{tabular}

Source: The Center for Responsive Politics, compiled from data released by the Federal Election Commission, July 1, 2000 
of health care benefit, use medical necessity - the smart bomb of managed care.” The issue of denying care based on medical necessity is spreading faster than lightning.

We are progressing well, having experienced several successes that will assist us in the development of interventional pain medicine and the preservation of its future. At this time, I would leave to the imagination of members and potential members and other interventional pain specialists, billing experts, and lobbyists to assimilate the information and judge fairly, though I do emphasize the word "fair."

Finally, it would be unfair to not thank the many individuals who have contributed to these monumental efforts. First and foremost, it is my family that has endured the loss of valuable time but also personal and financial sacrifices. Thus, I would like to thank my wonderful wife, Chandra, who has been supportive and encouraging in my efforts. I also would like to thank my three children, Anu, Sunil and Kavita, who not only have understood the intensity of this endeavor, but also supported with their time and input. Of course, I have to thank the staff of the Pain Management Center of Paducah for its immense support, not only from administrative employees, but nurses, technologists, transcriptionists. Special thanks to: Bert Fellows, Coordinator of ASIPP, who spent innumerable hours on the projects; Vidyasagar Pampati, Statistician Analyst and Programmer; Tonie Hatton and Denise Pratt, Transcriptionists; and Paula Benson, Darlene Harper, Kevin Court, Ben Lawrence, and Trish Burks. Apart from the help from home and office, we have also received substantial support from various members of the organization, including Vijay Singh, MD; David Kloth, MD; Kenneth Varley, MD; Andrea Trescot, MD; Bentley Ogoke, MD; Joseph Fortin, DO; Cyrus Bakhit, MD; Jose Rivera, MD; A. Ghafoor Baha, MD; Gabor Racz, MD; Elmer Dunbar, MD; Kunnathu Geevarghese, MD; Joseph Waling, MD; Peter Wright, MD; Steven Rupert, DO; Boris Pilch, MD; Imad Rasool, MD; Standiford Helm, MD; Mary Jo Curran, MD; Bhupinder
Saini, MD; Joseph Jasper, MD; Soloman Kamson, MD; and many, many others. Epimed, Myelotec, Arrow International, High Chemical, Clinical Education Services, Medtronics, Connecticut Pain Care, Ambulatory Surgery Center, (Paducah, KY), Pain Management Center of Paducah, and Southern Pain Specialists also have been of great assistance. In addition, I would like to thank our legal and lobbying group in Washington at Arent Fox: William Sarraille, Allison Shuren, Stacey Harbison, Mike McNamara, Jeff Peters, and Joann Felix. And finally, we could not have achieved any of this without the support from various congressional members, including Hon. Ed Whitfield, Hon. Mitch McConnell, Hon. Frank Pallone Jr, Hon. Anne Northup, Hon. Ron Lewis, Hon. John Rockefeller, Hon. Ron Wyden, Hon. Pete Stark, Hon. Chip Pickering, Hon. Ken Lucas, Hon. Bill Thomas, Hon. John Dingell, Hon. Bart Stupak, Hon. Don Nickles and Hon. Sherrod Brown. Last but not least, I would also like to thank other organizations that have supported our efforts, including: North American Spine Society, International Spinal Injection Society, Federated Ambulatory Surgery Center Association, and others.

While there is hope that the "real" new millennium will be a new beginning for interventional pain medicine, the daunting task of achieving unity and expanding the practice of effective and ethical interventional pain medicine still lies ahead of us. I'll close with a favorite quote from John F. Kennedy: "There are risks and costs to a program of action. But they are far less than the long range risks and costs of comfortable inactions." 